УДК 711.455(2):712(4/9)

ТРАНСГРАНИЧНЫЕ СЕКТОРАЛЬНО-КОЛЬЦЕВЫЕ СТРУКТУРЫ

ВОСТОЧНОГО СТЫКА ГРАНИЦ РОССИИ, МОНГОЛИИ И КИТАЯ КАК МАТРИЦЫ ТЕРРИТОРИАЛЬНОЙ ОРГАНИЗАЦИИ ТУРИСТСКО-РЕКРЕАЦИОННОЙ ДЕЯТЕЛЬНОСТИ

${ }^{1}$ Новиков А.Н., ${ }^{2}$ Новикова М.С., ${ }^{1}$ Козырева К.С.

${ }^{1}$ ФББУ ВО «Забайкальский государственный университет», Чита, e-mail: geonov77@mail.ru; ${ }^{2}$ ФБУН «Институт природных ресурсов, экологии и криологии» Сибирского отделения Российской академии наук, Чита, e-mail: mars.novik@mail.ru

\begin{abstract}
В данной работе представлены результаты исследования трансграничных кольцевых физико-географических структур восточного стыка границ России, Монголии и Китая, напоминающих собой амфитеатр с центробежным увеличением высот от Улдза-Торейской равнины, на котором и расположен стык трёхграничья; и описывающуюся радиальной моделью. Составной частью данной модели являются лучевые и дуговые элементы, которые делятся тремя границами на сектора. В дополнение к радиальности, обусловленной высотой местности, наблюдается ортогональность, выраженная в преобладающей направленности с юго-запада на северо-восток протяжённости горных хребтов. Выявленная в представленной работе дополнительность двух моделей выражает физико-географическую матрицу, детерминирующую, например, не только современную транспортно-расселенческую структуризацию, но и будущую туристско-рекреационную пространственную трансграничную организацию.
\end{abstract}

Ключевые слова: граница, Забайкальский край, Китай, кольцевые структуры, Монголия, туристскорекреационная деятельность

\title{
TRANSBOUNDARY SECTORAL-RING STRUCTURE EASTERN JUNCTION OF THE BORDERS RUSSIA, MONGOLIA AND CHINA AS MATRIX TERRITORIAL ORGANIZATION OF TOURIST-RECREATIONAL ACTIVITIES
}

\author{
${ }^{1}$ Novikov A.N., ${ }^{2}$ Novikova M.S., ${ }^{1}$ Kozyreva K.S. \\ ${ }^{1}$ Transbaikal State University, Chita, e-mail: geonov77@mail.ru; \\ ${ }^{2}$ Institute of Natural Resources, Ecology and Cryology Siberian Branch of the Russian Academy \\ of Sciences, Chita, e-mail:mars.novik@mail.ru
}

\begin{abstract}
In this paper, we present the results of an investigation of the transboundary ring physico-geographical structures of the eastern junction of the borders of Russia, Mongolia and China, resembling an amphitheater with a centrifugal increase in elevations from the Uldza-Torei plain, on which the three-bounded junction is located; And described by a radial model. Part of this model are ray and arc elements, which are divided into three sectors by sectors. In addition to the radiality due to the height of the terrain, orthogonality is observed, expressed in the predominant direction from the southwest to the northeast of the extent of the mountain ranges. The complementarity of the two models revealed in the presented work expresses the physico-geographical matrix, determining, for example, not only modern transport and settlement structure, but also the future tourist-recreational spatial crossborder organization.
\end{abstract}

Keywords: border, Chita region, China, ring structures, Mongolia, tourist and recreational activities

Современные потребности развития туристской деятельности на трансграничных территориях порождают необходимость разработки прогноза и стратегии её развития, как скоординированного процесса по обеим сторонам от границы, а в случае с международным трансграничным трёхзвенным регионом (МТТР) - между тремя сторонами от точки стыка трёхграничья. Прийти к согласованности между двумя сторонами бывает очень сложно, а между тремя сторонами поиск согласия ещё больше усложняется. Проведённые А.Н. Новиковым [8; 9] исследования взаимной организации природных и транспортно-расселенческих структур MTTP восточного стыка границ России, Монголии и Китая показали, что физико-гео- графические структуры (рельеф, природные зоны) наряду с государственной границей и стыком трёхграничья образуют географическую матрицу, которая предопределяет территориализацию общественной жизни.

В зарубежной науке МТТР рассматривают: Маркус Лейбинз (М. Leibenath) [19], анализируя причины, формы и последствия сотрудничества приграничных территорий стыка границ Германии, Польши и Чехии, отмечает, что имея сложную историю, они характеризуются экономическими диспропорциями, отсутствием общих идентичностей; Роберт Книппшилд (R. Knippschild) [18], отмечая, что физические барьеры для интеграции были сняты с вступлением в силу в 2007 г. Шенгенского соглашения; Пи- 
тер Джурзек (Peter Jurczek) [17], анализируя правовые, институциональные и ментальные барьеры, которые препятствуют трёхсторонней интеграции; А. Джакоб и А. Суше (L. Jacob, A. Suchet) [16], рассматривая трансграничный регион Эспас Монблан (Espace Mont-Blanc) на стыке границ Италии, Франции и Швейцарии, поднимают проблему определения внешнего периметра (внешних границ), ставят вопрос охраны природы как первопричину трёхсторонней трансграничной интеграции, за которой последуют вопросы координации сельскохозяйственного природопользования и экологического туризма.

В представленной работе авторы ставят целью, опираясь на опыт изучения закономерностей пространственного размещения природы, населения и хозяйства МТТР восточного стыка границ России, Монголии и Китая, сделать прогноз возможной и целесообразной территориализации туристской деятельности.

Проблема организации трансграничной туристской деятельности приграничья трёх стран выражается в асимметрии уровней развития инфраструктуры, асинхронности темпов реализации социально-экономических проектов в сфере туризма, разности технических, правовых и ментальных норм и стандартов организации обслуживания туристов, что затрудняет создание единой стратегии трансграничной (территориальной) организации туристской деятельности у стыка границ трёх стран.

Забайкальский край в рамках трансграничного трёхзвенного региона должен включиться в реализацию программы создания экономического коридора Китай Монголия - Россия, подписанной летом 2016 г. в Ташкенте. Научное сообщество должно обеспечить реализацию этой программы релевантной географической информацией в виде теоретических моделей, концепций и сценариев развития.

\section{Данные о методологии и методике исследования (Methods)}

Кольцевая пространственная организация объектов широко распространена как в макромире (орбиты планет вокруг звёзд), так и микромире (орбиты электронов вокруг ядра). В реальности мезомира кольцевая организация географических объектов тоже имеет место. Среди исследований посвящённых изучению кольцевых территориальных структур в геологии и геофизике, отметим работы М.З. Глуховского, М.И. Кузьмина [4], М.Н. Смирновой [13].
В политической географии кольцевая организация территориального могущества проанализирована В.П. Семёновым-ТяньШанским [12]. В географии природопользования концепцию кольцевых структур с центральной активной зоной сформулировал В.Л. Мартынов [6], а в географии населения и хозяйства кольцевой организацией занимается М.Д. Шарыгин [15]. Все отмеченные исследования объединяет только кольцевая территориальная организация исследуемых объектов; внутреннее строение, происхождение и функциональность объектов разная.

\section{Результаты исследования и их обсуждение}

MTTP восточного стыка границ России, Монголии и Китая в орографическом плане напоминает амфитеатр, где в центре располагается Улдза-Торейская равнина, окруженная горами с центробежным увеличением абсолютных высот. Именно на этой равнине располагается восточный стык государсвенных границ России, Монголии и Китая.

А.Т. Напрасников, сделавший гидролого-климатическое обоснование Забайкальской природной территории как геоэкологического ядра Евразии с характерной для него орографо-климатической изоляцией, писал: «Забайкалье представляет собой огромное мегапонижение, окружённое горами: на западе - Хамар-Дабанским и Баргузинскими хребтами; на севере - Северо-Байкальским и Становыми нагорьями; на востоке - Олёкминским Становиком и Большим Хинганом; на юге (в Монголии и Китае) - хребтами Монгольских Альп, Хингана, Хэнтэя и Иньшина» [7, с. 107]. Описанную географическую систему можно сравнить с амфитеатром. Структура амфитеатра - это радиальная модель. Кроме радиальной модели, территориальные структуры описываются ортогональной моделью. Ортогональность обусловлена преимущественной ориентацией хребтов с юго-запада на северо-восток. Такая ориентация наблюдается на западе у озера Байкал, а на востоке - у тихоокеанского побережья в Приморском крае. Две модели дополняют друг друга. Например, в ортогональной модели имеются чёткие черты концентричности. Стороны квадратов, образующиеся в результате пересечения решётчатых структур (горных хребтов и дорог, рек и дорог, дорог проходящих по котловине параллельно хребтам и пересекающих их), превращаются в концентрические круги. Действительно, в реальности дороги в межгорных котловинах проходят 
параллельно рекам, а те имеют дуговидные формы, впрочем, как и горные хребты, многие из которых тоже имеют черты дуговидности [8].

Как можно заметить при наложении одной модели на другую (рис. 1), квадраты трансформируются во вписанные друг в друга круги, расходящиеся концентрично от стыка трёх границ. В реальности это отклонение конфигурации хребтов и рек от линейной к дуговидной относительно стыка. В пределах Забайкальского края наблюдается стыкоцентричная дифференциация плотности транспортно-расселенческих структур (рис. 2), расчитанной авторами по методике Г.А. Гольца [2].

Представленную модель, возникшую в результате совмещения ортогональной и радиальной, можно отнести к секторально-кольцевой форме дисторсии в понимании Б.Б. Родомана [11].

Секторально-кольцевая территориализачия туристско-рекреационной деятельности. Секторально-кольцевая дополнительность выражает дискретноконтинуальную сущность трансграничных структур МТТР. Дискретная (дуго-луче- вая) организация туристско-рекреационных маршрутов в виде секторов и континуальная - в виде колец складывающихся из дуг и, таким образом, преодолевающих эту дискретность. Каждый способ имеет свою специфику. Конечно, в основе лежат сответствующие конфигурации элементов трансграничной транспортной системы.

Секторальное влияние приграничного положения.

В МТТР каждая приграничная сторона - это дуго-лучевой сектор. Взаимодействие между секторами может складываться по различным сценариям.

В зависимости от уровня развития контактных функций границы МТTР представляют собой следующие варианты: двухстороннего взаимодействия, осуществляющие трансграничное взаимодействие между двумя звеньями, когда один из трёх участков государственной границы является контактным, а два других - барьерными; трёхстороннего взаимодействия, имеющего контактную функцию на всех трёх участках государственной границы. Возможен вариант отсутствия экономической контактности границы в масштабе МТТР.

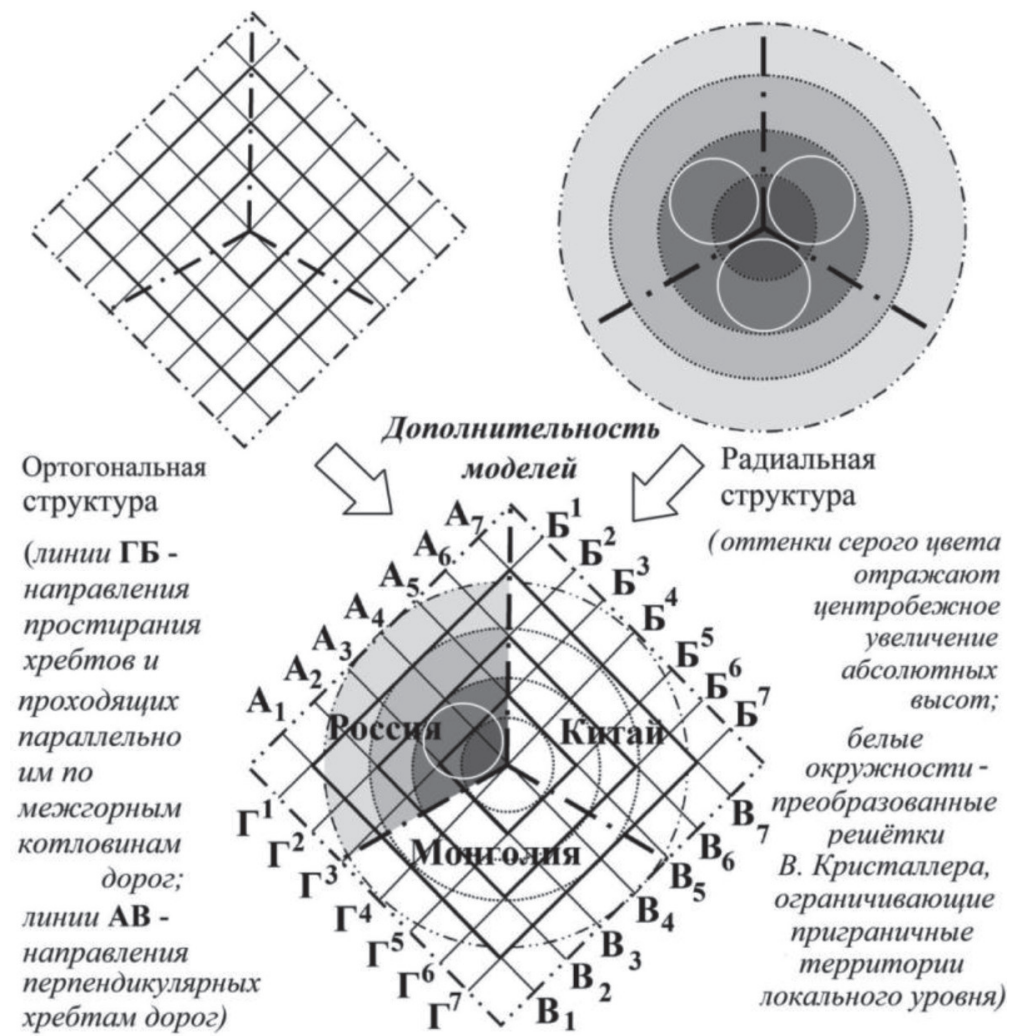

Рис. 1. Соотношение идеальных моделей МТТР восточного стыка границ России, Монголии и Китая 


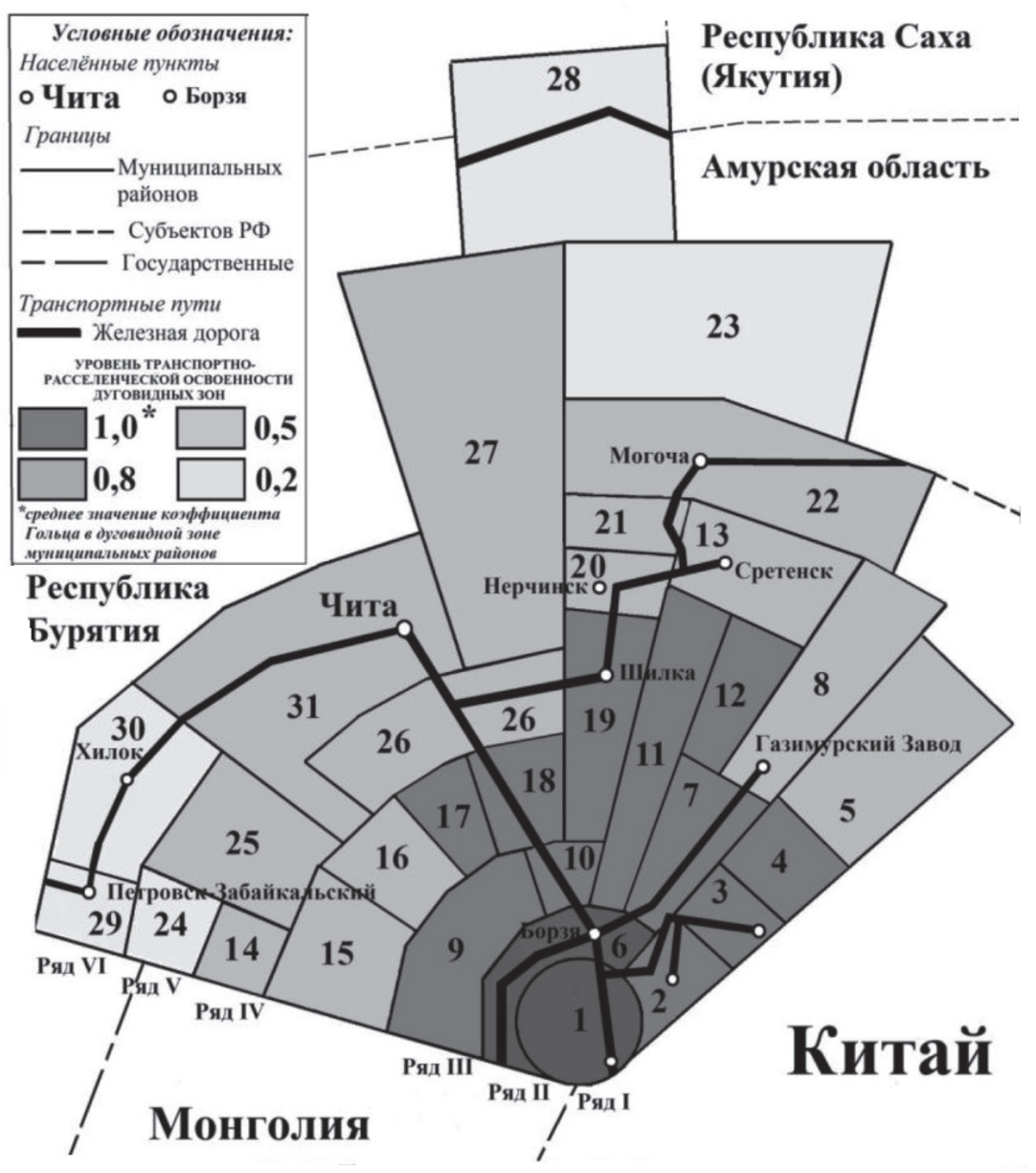

Рис. 2. Радиальная анаморфоза (дисторсия) Забайкальского края

Трёхзвенные территории, имеющие неполное - двухстороннее взаимодействие, находятся на начальной стадии трансграничной интеграции. Включению в интеграционные процессы третьего звена могут препятствовать различные причины: сложные физико-географические условия прохождения линии границы (горные цепи, реки, болота, леса). Возможны причины геополитического характера: политический режим, международное игнорирование. Есть и причины экономического характера: слабое развитие приграничной инфраструктуры или полное её отсутствие, сочетающееся с низким уровнем освоенности приграничной территории.

В Забайкальском крае складывается приграничная дуго-лучевая структура туристско-рекреационных маршрутов, её основа - это соответствующая конфигурация Транссибирской железной дороги: дуга «Петровск-Забайкальский - Чита - Мого- ча», а луч «Забайкальск - Чита». Конечно, можно выделить сектора меньшего масштаба, где имеется дуго-лучевая организация. Например, междуречье Газимура и Аргуни, на дуго-лучевидность трасс освоения которого обратили внимание: в хозяйственном плане М.С. Новикова [10], а в информационном - А.А. Соколова [14].

Кольцевые структуры - это направления взаимопроникновения, туристические потоки устремляются по дуговидным трансграничным трассам, которые, смыкаясь на границе, могут закольцовываться. В идеале по мере удаления от стыка границ трёх государств должны сменять друг друга такие кольцевые трассы, у которых должна увеличиваться длина дуг, а региональные туристичесие потоки сменяться глобальными, которые закольцовывают мировые аттракторы. Например, вокруг восточного стыка границ России, Монголии и Китая это закольцовывание триады «Байкал - Улан-Ба- 
тор (объекты связанные с Чингисханом) Великая китайская стена».

На региональном уровне в масштабе MTTP восточного стыка границ России, Монголии и Китая охватывает Забайкальский край, аймак Дорнод (Монголия) и Автономный район Внутреннюю Монголию (Китай). На уровне географического ядра МТТР оптимальным вариантом организации международных туристских маршрутов является их закольцованность в Далайнорской котловине, например по озерам (Зун-Торей - Борун-Торей - Хух-Нуур - Буйр-Нуур (Хулун-Буйр) Далайнор) или сответствующим ООПТ разного ранга (Даурский биосферный заповедник, «Монгол Дауур» и «Далайнор» и др.). Кольцевые маршруты могут сочетаться с проложением линейных маршрутов лучевой структуры от стыка границ трех стран или через стык границ трех стран (например, «Далайнор» Даурский биосферный заповедник - национальный парк «Алханай» - Ивано-Арахлейский заказник). Подобная пространственная организация - практически идеальное проявление трансграничных секторально-кольцевых структур в организации туристско-рекреационной деятельности. При удалении от ядра МТТР четкость кольцевых структур несколько снижается и ярче проявляются лучевые структуры. Закольцовывать в отдельные туристские маршруты возможна через дуговые структуры разной протяжености. В частности, аттрактами кольцевых маршрутов, образованных тремя дуговыми структурами на территории сопредельных стран, могут выступать природные и истрико-культурные объекты, связанные с именем Чингисхана: Ворота Чингисхана-Чаша Чингисхана-Вал Чингисхана (Забайкальский край); Мавзолей Чингисхана, храм Чингисхана (АР Внутреняя Монголия), Бурхан-Халдун, деревня Дагал (Дорнод аймак). Дуговые структуры можно выделить на основе исторических объектов, связаных с военными действиями на реке Халхин-Гол (Музей боевой славы ХалхинГол, Дом-музей Г.К. Жукова, собственно места боевых действий, World Anti-fascist War Hailar Memorial Park), которые связывают Дорнод аймак и Внутреннюю Монголию по линии Чойболсан - поселок Сумбэр - Хайлар.

Сочетание дуговых и лучевых структур прослеживается при организаци маршрутов религиозного туризма - одного из наиболее целесообразных в реализации туристского потенциала Забайкальского края [3]. Выделяются дуговые структуры, связанные с буддизмом (Читинский дацан - Агинский дацан - «Алханай», Ганжурский дацан (г. Хай- лар) - храм Утасы - монастырь Да Чжао (г. Хух-Хото) и комплекс Их Бурхант (пос. Халхгол) - монастырь Данраг (г. Чойбалсан)), а на территории Забайкальского края - с православием (озеро Иргень, Кафедральный собор Казанской иконы Божией Матери, Успенская церковь в с. Калинино и др.). Таким образом, в пространственной организации религиозного туризма данного МТТР можно говорить о кольцевой структуре туристских маршрутов только относительно буддизма или межконфессиональных туристических маршрутов двух мировых религий; закольцованных структур православного религиозного туризма в границах МТТР нет. Теоретически в кольцевую структуру организации туристско-рекреационной деятельности укладываются и маршруты этнического (этнографического) туризма. Однако подобные трансграничные маршруты будут иметь бо́льшую протяженность и удаленность от центра МТTР (русское трехречье Агунь-Тэлбур-Хаул (волость Шивэй, деревни Энхэ и Линьцзянь), Аолугуя; традиционное природопользование коренных жителей сомонов Чулуунхороот, Баян-Уул, Дашбалбар и др.; быт и традиции семейских (Урлук, Архангельское, Красный Чикой и др.), бурят (Агинский, Дульдургинский и Могойтуйский районы)), что влечет усиление линейной симметрии при удалении от стыка границ, и их кольцевая структура будет несколько более условной.

В перспективе в практике туристской деятельности интерес представляют природные аттракты мирового значения, например приуроченные к зоне тектонических разломов озера Ничатка - Леприндо - Байкал Хубсугул - дугообразная структура, определющая соотвествующую генеральную нитку туристских маршрутов или районы палеонтологических находок динозавров на территории Забайкальского края (Падь Кулинда), провинции Ляонин в Китае и пустыня Гоби в Монголии.

\section{Заключение}

Освоение территории, которое К.П. Космачёв [5] и В.И. Блануца [1] рассматривают как последовательное развертывание сетевых структур, процесс многослойный, где каждый последующий слой разворачивается поверх предыдущего. Соответственно, предыдущие слои становятся не только базисом, но и матрицей для последующих. На данном утверждении может основываться географический прогноз. Секторально-кольцевая организация уже начинает проявляться в туристско-рекреационной структуризации 
восточного стыка границ России, Монголии и Китая. Этот важный момент необходимо учитывать для исключения противоестественных схем территориального планирования туристических маршрутов, а также скоординированной организации приграничных контактных звеньев.

Работа выполнена при финансовой поддержке гранта 226 ФГБОУ ВО «Забайкальский государственный университет».

\section{Список литературы}

1. Блануца В.И. Развёртывание информационно-коммуникационной сети как географический процесс (на примере становления сетевой структуры сибирской почты)/ В.И. Блануца. - М.: Инфра-М, 2016. - 246 с.

2. Гольц Г.А. Транспорт и расселение / Г.А. Гольц. - М.: Наука, 1981. - 248 с.

3. Горина К.В. Туристское позиционирование религиозных объектов Забайкальского края в информационном пространстве разных территориальных уровней / К.В. Горина, К.С. Козырева, А.Н. Новиков // Региональные исследования. -2015 . - № 1. - С. 78-87.

4. Глуховский М.3. Котуйканская кольцевая структура возможное свидетельство масштабного импактного события на севере Сибирского кратона / М.З. Глуховский, М.И. Кузьмин // Геология и геофизика. - 2013. - Т. 54, № 1. - С. 3-26.

5. Космачёв К.П. Пионерное освоение тайги (экономико-географические проблемы) / К.П. Космачёв. - Новосибирск: Наука, 1981. - 109 с.

6. Мартынов В.Л. Пространственная самоорганизация общества: взаимосвязи и взаимодействия: дис. ... Д-ра геогр. наук. - СПб., 2002. - 200 с.

7. Напрасников А.Т. Гидроголо-климатические системы: геоэкологический анализ / А.Т. Напрасников - Иркутск: Изд-во Ин-та географии СО РАН, 2003. - 143 с.

8. Новиков А.Н. Философско-географическая идеализация трансграничной организации природы, населения и хозяйства восточного стыка границ России, Монголии и Китая / А.Н. Новиков // Гуманитарный вектор. Серия: Философия. Культурология. - 2015. - № 2 (42). - С. 81-88.

9. Новиков А.Н. Приграничное положение Забайкальского края в трансграничном трёхзвенном регионе: роль в территориальной организации населения и хозяйства А.Н. Новиков - Чита: Изд-во Забайкал. гос. ун-т., 2015. - 94 с.

10. Новикова М.С. Экономико-географические особенности освоения юго-восточных районов Забайкальского края / М.С. Новикова. - Новосибирск: Гео, 2014. - 161 с.

11. Родоман Б.Б. Территориальные ареалы и сети. Очерки теоретической географии / Б.Б. Родоман. - Смоленск: Ойкумена, 1999. - 256 с

12. Семёнов-Тянь-Шанский В.П. О могущественном территориальном владении применительно к России В.П. Семёнов-Тянь-Шанский // Изв. Император. Рус. геогр. о-ва. - 1915. - Т. 51. - вып. 8. - С. 425-457.

13. Смирнова М.Н. Нефтегазоносные кольцевые структуры - каналы миграции углеводородных флюидов М.Н. Смирнова // Геология, геофизика и разработка нефтяных и газовых месторождений. - 2002. - № 5. - С. 20-26.

14. Соколова А.А. Аргунское поречье: территориальная дифференциация информационного пространства (на материале русской диалектной лексикографии и топонимиматериале русской диалектной лексикографии и топоними№ 1. - С. 161-169.

15. Шарыгин М.Д. Территориальные общественные системы (региональный и локальный уровни организации и управления): избр. тр. / М.Д. Шарыгин. - Пермь: Изд-во ПГУ, 2003. - $260 \mathrm{c}$.

16. Jacob L. Territorial thinking and the legal framework in cross-border cooperation: the recent situation and fieldwork results in the western Alps / L. Jacob, A. Suchet // European Journal of Geography. - 2013. - Vol. 4, № 4. - P. 20-32.

17. Jurczek P. Cross-border cooperation in the GermanCzech-Polish border region at the turn of the century / P. Jurczek // Journal of Borderlands Studies. - 2002. - Vol. 7, Issue 2. P. 97-104.
18. Knippschild R. Cross-Border Spatial Planning: Understanding, Designing and Managing Cooperation Processes in the German-Polish-Czech Borderland / R. Knippschild // European Planning Studies. - 2011. - Vol. 19, Issue 4. - P. 629-645.

19. Leibenath M. Europeanisation of Cross-border Governance? A Case Study on the Cause, Form and Consequences of a Co-operation Project in the German-Polish-Czech Border Triangle / M. Leibenath // Space and Polity. - 2007. - Vol. 11, Issue 2. - P. 151-167.

\section{References}

1. Blanuca V.I. Razvjortyvanie informacionno-kommunikacionnoj seti kak geograficheskij process (na primere stanovlenija setevoj struktury sibirskoj pochty) / V.I. Blanuca. M.: Infra-M, 2016. 246 p.

2. Golc G.A. Transport i rasselenie / G.A. Golc. M.: Nauka, 1981. 248 p.

3. Gorina K.V. Turistskoe pozicionirovanie religioznyh obektov Zabajkalskogo kraja $\mathrm{v}$ informacionnom prostranstve raznyh territorialnyh urovnej / K.V. Gorina, K.S. Kozyreva, A.N. Novikov // Regionalnye issledovanija. 2015. no. 1. pp. 78-87.

4. Gluhovskij M.Z. Kotujkanskaja kolcevaja struktura: vozmozhnoe svidetelstvo masshtabnogo impaktnogo sobytija na severe Sibirskogo kratona / M.Z. Gluhovskij, M.I. Kuzmin // Geologija i geofizika. 2013. -T. 54, no. 1. pp. 3-26.

5. Kosmachjov K.P. Pionernoe osvoenie tajgi (jekonomikogeograficheskie problemy)/ K.P. Kosmachjov. Novosibirsk: Nauka, 1981. 109 p.

6. Martynov V.L. Prostranstvennaja samoorganizacija obshhestva: vzaimosvjazi i vzaimodejstvija: dis. ... d-ra geogr. nauk. SPb., 2002. 200 p

7. Naprasnikov A.T. Gidrogolo-klimaticheskie sistemy: geojekologicheskij analiz / A.T. Naprasnikov Irkutsk: Izd-vo Inta geografii SO RÄN, 2003. $143 \mathrm{p}$.

8. Novikov A.N. Filosofsko-geograficheskaja idealizacija transgranichnoj organizacii prirody, naselenija i hozjajstva vostochnogo styka granic Rossii, Mongolii i Kitaja / A.N. Novikov // Gumanitarnyj vektor. Serija: Filosofija. Kulturologija. 2015. no. 2 (42). pp. 81-88.

9. Novikov A.N. Prigranichnoe polozhenie Zabajkalskogo kraja $\mathrm{v}$ transgranichnom trjohzvennom regione: rol $\mathrm{v}$ territorialnoj organizacii naselenija i hozjajstva / A.N. Novikov Chita: Izd-vo Zabajkal. gos. un-t., 2015. 94 p.

10. Novikova M.S. Jekonomiko-geograficheskie osobennosti osvoenija jugo-vostochnyh rajonov Zabajkalskogo kraja / M.S. Novikova. Novosibirsk: Geo, 2014. 161 p.

11. Rodoman B.B. Territorialnye arealy i seti. Ocherki teoreticheskoj geografii / B.B. Rodoman. Smolensk: Ojkumena, 1999. $256 \mathrm{p}$

12. Semjonov-Tjan-Shanskij V.P. O mogushhestvennom territorialnom vladenii primenitelno k Rossii / V.P. SemjonovTjan-Shanskij // Izv. Imperator. Rus. geogr. o-va. 1915. T. 51. vyp. 8. pp. $425-457$.

13. Smirnova M.N. Neftegazonosnye kolcevye struktury kanaly migracii uglevodorodnyh fljuidov / M.N. Smirnova// Geologija, geofizika i razrabotka neftjanyh i gazovyh mestorozhdenij. 2002. no. 5. pp. 20-26.

14. Sokolova A.A. Argunskoe poreche: territorialnaja differenciacija informacionnogo prostranstva (na materiale russkoj dialektnoj leksikografii i toponimiki) / A.A. Sokolova // Gumanitarnyj vektor. 2017. T. 12, no. 1. pp. 161-169.

15. Sharygin M.D. Territorialnye obshhestvennye sistemy (regionalnyj i lokalnyj urovni organizacii i upravlenija): izbr. tr. / M.D. Sharygin. Perm: Izd-vo PGU, 2003. 260 p.

16. Jacob L. Territorial thinking and the legal framework in cross-border cooperation: the recent situation and fieldwork results in the western Alps / L. Jacob, A. Suchet // European Journal of Geography // 2013. - Vol. 4, № 4. - P. 20-32.

17. Jurczek P. Cross-border cooperation in the GermanCzech-Polish border region at the turn of the century / P. Jurczek // Journal of Borderlands Studies. 2002. Vol. 7, Issue 2. pp. 97-104.

18. Knippschild R. Cross-Border Spatial Planning: Understanding, Designing and Managing Cooperation Processes in the German-Polish-Czech Borderland / R. Knippschild // European Planning Studies. 2011. Vol. 19, Issue 4. pp. 629-645.

19. Leibenath M. Europeanisation of Cross-border Governance? A Case Study on the Cause, Form and Consequences of a Co-operation Project in the German-Polish-Czech Border Triangle / M. Leibenath // Space and Polity. 2007. Vol. 11, Issue 2. pp. $151-167$. 